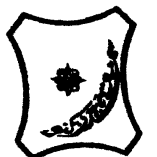

Bayero Journal of Pure and Applied Sciences, 8(1): 153 - 159

Received: February, 2015

Accepted: June, 2015

ISSN $2006-6996$

\title{
NOVEL APPLICATIONS OF LOCALLY SOURCED MONTMORILLONITE (MMT) CLAY AS A DISINTEGRANT IN THE FORMULATION OF PHARMACEUTICAL PRODUCT
}

\author{
*Okolo, P.O., Omonmhenle, S.I., Abdulsalaam, A.O.and Ofunne, C.N. \\ Materials Testing Research Centre, Department of Chemistry, University of Benin, Benin City. Nigeria. \\ *Correspondence author: okolopao@yahoo.com
}

\begin{abstract}
This work explores the application of a locally sourced raw material, montmorillonite (MMT) clay, as a disintegrant in the formulation of an analgesic pharmaceutical product - paracetamol. The raw MMT was refined and treated with $0.1 \mathrm{M} \mathrm{NaCl}$ to yield sodium montmorillonite (NaMMT) and the powder properties established in this work were compared with those of purified kaolinite (KO) clay and a reference standard disintegrant - maize starch (MS). Separately, the NaMMT, KO and MS powders were employed as disintegrants to compound paracetamol tablets. Some of the physical properties of the tablets were determined. Results of some powder properties showed that NaMMT and $K O$ had superior angles of repose $\left(40.20^{\circ}\right.$ and $34.40^{\circ}$, respectively) compared with the reference standard disintegrant MS (56.00\%). Sodium montmorillonite (NaMMT) showed better swelling capacity (1.81) than both $K O$ and MS (1.40 and 1.56, respectively), while MS and NaMMT exhibited comparable water retention capacity (3.04\% and $2.90 \%$, respectively). The porosity of MS (31.94\%) was only slightly better than that of NaMMT (30.00\%). For the physical properties of the tablets, the dissolution characteristic of NaMMT was slightly better than that of MS: for example, the percentage amount of $15 \%$ NaMMT and MS dissolved in $0.1 \mathrm{M} \mathrm{HCl}$ solution at 30 minutes duration were $75.40 \%$ and $74.10 \%$, respectively; and at 50 minutes duration, it was $85.10 \%$ and $82.10 \%$, respectively. On the other hand, the disintegration property of MS (1.54min) was slight/y better than that of NaMMT (2.10min). Kaolinite (KO) failed both the dissolution and integration tests, with only $0.31 \%$ dissolving even after $1 \mathrm{hr}$ and requiring more than $30 \mathrm{~min}$ to disintegrate. The friability and hardness tests showed that NaMMT was superior to both MS and KO. Overall, the sodium montmorillonite (NaMMT) was found to hold strong prospect as a disintegrant in the formulation and compounding of certain solid, compact pharmaceutical dosages.
\end{abstract}

Keywords: Compact dosages, disintegrants, local raw material, montmorillonite clay, pharmaceutics.

\section{INTRODUCTON}

The prohibitive cost of some drugs in certain third world countries necessitates the exploration of certain raw materials in the formulation of some pharmaceutical products. To formulate solid, compact dosages, the active principles are usually uniformly dispersed in an inert solid vehicle referred to as a disintegrant. When pharmaceutical preparations are administered in the form of tablets, the active principles (drugs) are liberated as the tablet absorbs liquid, swells, dissolves and eventually disintegrates in the patient's stomach. An ideal disintegrant would cause the tablet to release at least $70 \%$ of the drugs in not more than 30 minutes (Reghvendra and Saraswaithi, 2012; Amodu, 2011).

Materials that have been employed as disintegrants include starch from: maize, cassava, yam, wheat, rice, pepino fruit, e.t.c; others are microcrystalline cellulose and modified cellulose gum (Iwuagwu and Okoli, 1992; Olayemi, 2008; Saleemula et al., 2010; Amodu, 2011). Some workers have used clay for different purposes in drug formulation. Kaolinite clay was found to possess superior lubricant properties in tableting at low concentrations $(0.2-1.0 \%)$ compared with the familiar lubricants, such as stearic acid and talc (Onyekweli, 1985; Oladimeji et al., 1997). Others have employed montmorillonite, polygorskite, kaolinite and talc as emulsifying, thickening or anticaking agents, due to their colloidal and thixotropic properties, in the preparation of syrups, suspensions, gels e.t.c.(Lagaly, 1989; Yuan and Murray, 1997; Van, 1977; Lagaly, 2006).

This work seeks to contribute to the search for the use of local raw materials in the formulation of cheap and effective pharmaceutical products. It specifically intends to employ montmorillonite clay as the sole disintegrant in the formulation and compounding of an analgesic drug - paracetamol tablets. Results would be compared with those of a reference standard disintegrant - the maize starch (MS).

\section{MATERIALS AND METHODS}

Pharmaceutical-grade

powders of paracetamol B.P., maize starch B.P., magnesium stearate and analytical grade sodium chloride $(\mathrm{BDH}$, England) were used as obtained. 
Montmorillonite clay sample was collected from Okada in Ovia North East Local Government Area of Edo State, Nigeria, while kaolinite clay sample was collected from Okwaehe in Orionwo Local Government Area of Edo State, Nigeria. These clay samples were properly identified by experts in Geology Department, University of Benin, Benin City, Nigeria.

\section{Purification and Modification of Clay Samples}

The purification and chemical modification of the native montmorillonite clay were based on the methods of Bergaya et al., 2006. Air-dried native montmorillonite clay sample was crushed in a mortar and $500.0 \mathrm{~g}$ of the clay dispersed in $4.0 \mathrm{~L}$ of deionize water. The suspension was swirled thoroughly for $5 \mathrm{~min}$, and then filtered at room temperature $\left(28^{\circ} \mathrm{C}\right)$ through mesh size of $200 \mu \mathrm{m}$ in order to screen out non-clay materials. The sediments was dried in a hot-air oven (Drying Oven. DHG - 9023A. B. Bran Scientific \& Instruments Company, England) at $105^{\circ} \mathrm{C}$ to constant weight. The dry sediment was then dispersed in $1.0 \mathrm{~L} 0.1 \mathrm{M} \mathrm{NaCl}$ aqueous solution and stirred for $5 \mathrm{hrs}$ and filtered again. The resulting sediment was washed with deionized water until free of chloride ions as tested by $\mathrm{AgNO}_{3}$ solution, to obtain the Na-montmorillonite (NaMMT) (Bergaya et al., 2006). The NaMMT was then oven dried at $105^{\circ} \mathrm{C}$ to constant weight, pulverized and sieved through $64 \mu \mathrm{m}$ mesh size to get fine powder. The native kaolinite clay sample was similarly purified, except that no sodium analogue was made.

\section{Determination of Physicochemical Properties of NaMMT and the Purified Kaolinite Powders Swelling Capacity:}

The swelling capacity was estimated by the methods of Bowen and Vadino, 1984. Five grams $(5.0 \mathrm{~g})$ of purified clay sample were placed in a $100.0 \mathrm{~mL}$ measuring cylinder and the bulk volume $\left(V_{x}\right)$ noted. Deionized water $(85.0 \mathrm{~mL})$ was added and the measuring cylinder agitated to disperse the clay. The volume of the suspension was made up $100.0 \mathrm{~mL}$ with more deionized water. The dispersion was allowed to stand for $24 \mathrm{hrs}$ after which the final volume of the sediment $\left(V_{y}\right)$ was read and noted. The swelling capacity was calculated as:

Swelling capacity $=V_{y} / V_{r}$.

The swelling capacity tests were repeated in triplicates and the average value calculated.

\section{Water Retention Capacity}

The water retention capacity was determined based on the methods of Komblum and Stoopak, 1973 and Ring, 1985. One gram (1.0g) of the purified clay sample was placed in $15.0 \mathrm{~mL}$ plastic centrifuge tube to which $10.0 \mathrm{~mL}$ deionized water was added and then stoppered. The contents were mixed for $2 \mathrm{~min}$. The mixture was allowed to stand for $10 \mathrm{~min}$ and then centrifuged at 5000 r.p.m. for 25min (CENTRIFUGE MPW 53/MED INSTRMENTS, POLAND). The resulting supernatant was carefully decanted and the sediment weighed. The water retention capacity was taken as the ratio of sediment weight $\left(W_{y}\right)$ to the dry sample weight $\left(W_{x}\right)$.

Water retention capacity $=W_{y} / W_{x}$. Triplicate results were obtained and the average used.

\section{Bulk and Tapped Densities}

The bulk and tapped densities were determined using the methods described by Jideonwo et al., 2013, and Alanzi, 2007. Ten grams $(10.0 \mathrm{~g})$ each of the purified clay samples were weighed on the analytical balance (Mettler Instruments 163, Switzerland) and transferred into a $100-\mathrm{mL}$ measuring cylinder. The bulk volume $\left(\mathrm{V}_{\mathrm{b}}\right)$ was recorded. The cylinder was then gently tapped on the wooden platform until the volume occupied by the clay sample became constant. The tapped volume $\left(V_{t}\right)$ was then recorded. The bulk and tapped densities ( $D_{b}$ and $D_{t}$, respectively) were calculated as the ratio of weight $(w)$ to volume:

$\mathrm{D}_{\mathrm{t}}=W / V_{1} ; \mathrm{D}_{\mathrm{b}}=W / V_{b}$. Triplicate results were obtained and the average used.

\section{True Density}

Specific gravity bottle was filled with the liquid paraffin and the weight noted. It was then poured out and the bottle washed clean and dried. One gramme $(1.0 \mathrm{~g})$ of the oven - dried powder was introduced into the bottle, liquid paraffin was then poured into the bottle until it was filled. The new weight was noted. True density was calculated using the formula (Olayemi, 2008):

$$
D_{t}=\frac{w \times d}{(a+w)-b}
$$

Where $D_{t}=$ True density; $\quad d=$ Specific gravity of liquid paraffin;

$a=$ Weight of bottle + liquid paraffin; and $\mathrm{b}=$ Weight of bottle + liquid paraffin + sample; $w=$ Weight of sample.

\section{Hausner's Ratio}

Hausner's ratio was calculated from the ratio of the tapped density to bulk density (Nwuluka et al., 2010):

Hausner's ratio $=1 / D_{b}$

\section{Angle of Repose}

The angle of repose was determined using the methods of Odeniyi et al., 2011. Ten grams $(10.0 \mathrm{~g})$ of the purified (dry) clay samples were each poured via a funnel into an open ended glass tube $(1 \mathrm{~cm}$ internal diameter) with its bottom resting on a horizontal surface. On gradually raising the cylinder vertically, the purified clay flowed out and formed a conical heap as a result of gravitational force.The height $(h)$ of the cone and the radius ( $r$ ) of its circular base were measured. The angle of repose () was calculated using the relationship: $\alpha-\tan ^{-1}\left(\frac{h}{r}\right)$ 


\section{pH Determination}

Two grams $(2.0 \mathrm{~g})$ of the purified clay samples were each poured into

$100-\mathrm{mL}$ measuring cylinder. De-ionized water was added up to the mark. The suspension was then agitated for $5 \mathrm{~min}$ and the $\mathrm{pH}$ determined with a $\mathrm{pH}$ meter (Raymond et al., 2006).

\section{Preparation of Granules}

Paracetamol granules were produced using the net granulation techniques of Hill, 2006. Paracetamol granules of three disintegrant ratios $(5 \%, 10 \%$ and $15 \%)$ were prepared from the sodium montmorillonite (NaMMT) clay and the refined kaolinite (KO) clay, respectively. The disintegrant properties of these ratios were compared with that of a reference standard disintegrant (maize starch, MS). For example, to produce $5 \%$ disintegrant (NaMMT) ratio in the paracetamol granule, $2.5 \mathrm{~g}$ of NaMMT powder was mixed with $50.0 \mathrm{~g}$ of paracetamol powder in a motar using small quantity of deionized water $(10.0 \mathrm{~mL})$ as granulating liquid, to form ' a smooth consistency. This was then used to produce the granules as listed bellow, in the case of the reference standard disintegrant.

The reference standard disintegrant granules were prepared by first mixing $10.0 \mathrm{~g}$ of the maize starch B.P. with $10.0 \mathrm{~mL}$ of deionized water to form a slurry, which was made up to $100-\mathrm{mL}$ volume with boiling deionized water $\left(100^{\circ} \mathrm{C}\right)$ to produce starch mucilage. The starch mucilage was added to $50.0 \mathrm{~g}$ dry paracetamol powder B.P., mixed gently until a moist smooth mass was formed. Subsequently, $5.0 \mathrm{~g}$ of additional dry maize starch B.P. was added extragranularly as the disintegrant. The entire mass was mixed thoroughly to produce a smooth consistency ( $10 \% \mathrm{MS}$, so called).

The smooth consistency was then screened through a 2-mm mesh, using a spatula. The resulting granules were dried in the hot-air oven at $40^{\circ} \mathrm{C}$ for $30 \mathrm{~min}$ after which it was re- screened through a $170-\mathrm{mm}$ mesh size using the spatula. Magnesium stearate $(1 \%)$ was finally added as lubricant, with final mixing.

\section{Compression of Granules into Tablets}

The granules were compressed into flatfaced tablets using a single punch tablet press (Erweka 400, Germany). The punch diameter used was $12 \mathrm{~mm}$, while the compression pressure was 7.5 units (Anthony et al., 2003).

\section{Quality Standard for the Tablet Weight Uniformity Test.}

Ten tablets from each batch of formulation were weighed individually on a mettler balance (Mettler Instruments 163, Switzerland) and the mean tablet weight was calculated (Amodu, 2011).

\section{Tablet Thickness}

The tablet thickness was determined using the micrometer screw gauge. Ten (10) tablets were picked randomly from each batch, and their respective thicknesses measured and expressed in $\mathrm{mm}$ and the mean value calculated (Amodu, 2011). Tablet Hardness

The hardness of the tablet, expressed as the crushing force, was determined using a Monsanto Hardness Tester, Model 2A (Manesty Machines Ltd, Spoke Liverpool, England). A tablet was held between a fixed anvil and a moving jaw and the force gradually increased until the tablet just fractured. The value of the force at this point gives a measure of the tablet's hardness in $\mathrm{kg}$ force. For each batch, the hardness of five (5) tablets were determined from which the average was calculated (Amodu, 2011).

\section{Tablet Friability}

Ten (10) tablets were randomly picked from each batch, dusted carefully and lightly until all surface powder was removed. The tablets were weighed $\left(\mathrm{W}_{1}\right)$ accurately with the mettler balance. They were placed inside the Friabilator (Erweka TA 48503, Germany) and operated (rotated) 100 times in 4 minutes, i.e 25 r.p.m.. After this the tablets were removed, dusted and reweighed $\left(\mathrm{W}_{2}\right)$. From the weight difference, friability (f) for each batch of tablets was determined as the percentage weight loss (Saleemula et al., 2010).

\section{Disintegration time for tablets}

The time required for six tablet per batch to disintegrate was determined using the Disintegrator (Manesty Tablet Disintegration Test Unit, MK. 4, 10.T.183, Manesty Machines, England). Distilled water thermostatically maintained at $37^{\circ} \mathrm{C}$ was used as the disintegration medium. The disintegration apparatus was calibrated to operate at thirty cycles per minute. The time taken for the last tablet or its fragment to pass through the mesh into the disintegration medium was recorded as the mean of the disintegration time for six tablets (British Pharmacopoeia, 2002).

\section{Dissolution rate for tablets}

Dissolution rate tests were carried out on the tablets based on the methods of Bai et al., 2011. A dissolution test apparatus (Multipurpose Drug Test Device, Model ST 7; G. B. CALEVA Ltd. Dorset, England) was used; six (6) tablets per batch were tested. The dissolution apparatus was set at a rotation speed of 100 r.p.m., maintaining the temperature thermostatically at $37 \pm 0.5^{\circ} \mathrm{C}$. The sample medium consisted of $800 \mathrm{~mL}$ of $0.1 \mathrm{M}$ aqueous $\mathrm{HCl}$ for paracetamol tablets. Ten millilitres $(10.0 \mathrm{~mL})$ of the sample medium was withdrawn at $10 \mathrm{~min}$ intervals. Each aliquot withdrawn was immediately replaced with an equal volume of dissolution medium maintained at the same temperature. A ten fold dilution of the withdrawn sample medium was done using deionized water before spectrophotometric determination of drug content, at $\lambda_{\max }$ of $242 \mathrm{~nm}$ (UV/VIS Spectrometer T70. PG Instruments Ltd, England). The percentage drug released was plotted against time $(\mathrm{min})$ to generate a dissolution rate curve (Bai at al., 2011). 


\section{Bajopas Volume 8 Number 1June, 2015}

The results of some physical characteristics of the two proposed disintegrant powders (NaMMT) and KO as compared with that of the reference standard disintegrant (MS) are presented in Table1.

The angle of repose is an indicator to the flow property of powders (Ring, 1985); good flow property may reduce the powder's ability to consolidate during vibrational flow and hence leads to production of uniform tablets. Table 1 reveals that NaMMT has superior angle of repose $\left(40.20^{\circ}\right)$ compared to the reference standard disintegrants MS $\left(56.00^{\circ}\right)$. The Hausner's ratio values are derived as the ratio of the tapped density over the bulk density and give an indication of the degree of densification of powder which could result from the vibration of the feed hopper during tableting. Since densification can adversely affect the uniformity of flow of powder into the die, the tablet uniformity may also be adversely affected. A high Hausner's ratio predicts significant densification of powders. It can be inferred from Table 1 that NaMMT powder favourably compares with MS with respect to densification phenomenon (Iwuagwu and Okoli, 1992).

Since water uptake invariably precedes the disintegration process, the determination of water retention capacity and swelling capacity of powders may predict their potentials as tablet disintegrants (Iwuagwu and Okoli, 1992). Table 1 reveals that NaMMT displayed a superior swelling capacity (1.81) than MS (1.56) and KO (1.40). Also, the NaMMT and MS exhibited better water retention capacities $2.90 \%$ and $3.04 \%$, respectively, than KO $(1.80 \%)$. The good swelling capacities of NaMMT and MS can easily be correlated with their high powder porosities $(30.00 \%$ and $31.94 \%$, respectively) as against $20.00 \%$ for KO. The excellent swelling capacity, water retention capacity and porosity displayed by NaMMT may be due to the smaller size of $\mathrm{Na}^{+}$ion compared with $\mathrm{Ca}^{2+}$ ion (Shannon, 1976) in the clay matrix: during modification of raw calcium montmorillonite (CaMMT), $\mathrm{Na}^{+}$ions replaced $\mathrm{Ca}^{2+}$ ions and invariably left behind porous structure that became NaMMT. Intuitively, it would appear that $\mathrm{Na}^{+}$ion being less electropositive and possessing higher hydration energy than $\mathrm{Ca}^{2+}$ ion (Lee, 1996) would readily bind onto the polar water molecules. This is in agreement with the findings of Kloprogge et al., 1999, who aver that clays with univalent interlayer cations swell more readily in aqueous systems than divalent and trivalent cation analogues. These factors synegystically confer excellent porosity, water retention capacity and swelling capacity on NaMMT which may finally translate to superb disintegrant properties in some tablet formulation.

Table 2 presents some physical properties of the paracetamol tablets formulated and compounded with the proposed disintegrants (NaMMT and KO) at different disintegrant concentrations, and compared with those prepared with a reference standard disintegrant, MS. It shows that the hardness of the tablets generally improved as the concentration of the disintegrant increased, within the range studied. However, the hardness of the tablets prepared with $15 \%$ NaMMT closely matched those made with the reference disintegrant MS (8.50 and 8.01, respectively). Friability tests reveal the extent the tablets can resist abrasion and chipping that might arise due to handling, transportation, e.t.c. Table 2 also shows that the friability of the batches of tablets were not significantly affected by the change in concentration of disintegrants. Since the maximum limit for friability (weight loss) is $0.8 \%$ (Amodu, 2011 and Odeniyi at al., 2011) all the tablets passed the friability tests; again the 15\% NaMMT formulation emerged as the best $(0.19 \%)$ compared with the $0.46 \%$ for the reference MS tablets.

The uniformity of tablets is important because it ensures that dosage of active ingredient does not vary from one tablet to another. Table 2 reveals that the uniformity of all the tablets, per batch was satisfactory. Hence the tablets' thickness, diameter and mean weight were uniform and favourably compared with the reference MS tablets. These good tablet qualities with respect to hardness, friability and uniformity are eloquent testimony of some superb powder properties of the disintegrants, such as angle of repose and Hausner's ratio (Ring 1985; Iwuagwu and Okoli, 1992). The good tableting quality displayed by kaolin in this work is in consonance with the findings of Anthony et al., 2003.

Tablet dissolution and bioavailability of the active ingredients are always invariably preceded by disintegration of the tablet. For most uncoated tablets, the maximum disintegration period is $30 \mathrm{~min}$ (Amodu, 2011). Table 2 reveals that the kaolinite (KO) tablets woefully failed the disintegration test, requiring more than $30 \mathrm{~min}$ to disintegrate, irrespective of disintegrant concentration in the range studied. The predominant elements in kaolinite, Al and Si, (Lee, 1996) are known to be unfavourably disposed towards water absorption, probably due to their relative large atomic sizes and low hydration energies compared to $\mathrm{Na}$ (Shannon, 1976 and Lee, 1996). Conversely, the disintegration qualities of the NaMMT tablets improved with increasing concentration of disintegrant within the range studied, with $15 \%$ NaMMT formulation closely matching that of the reference MS tablets $(2.10 \mathrm{~min}$ and $1.54 \mathrm{~min}$, respectively). The sodium ions in NaMMT being small sized, reasonably electronegative with higher hydration energy, coupled with high powder porosity in the disintegrant, and capillary actions, probably encouraged absorption of water into the matrix, leading to fast disintegration of the tablets (Washburn, 1921; Selkirk and Ganderton, 1970; Lee, 1996; Shannon, 1976). The overriding quality of a tablet depends on the rate at which active principles are released in an appropriate medium through dissolution. 
Bajopas Volume 8 Number 1June, 2015

Figures 1 and 2 summarize the dissolution and drug release properties of paracetamol tablets compounded with the two proposed disintegrants (NaMMT and KO) as compared with those of the reference standard disintegration MS. An ideal tablet releases at least $70 \%$ of the active ingredient in not more than 30minutes (Amodu, 2011). Figures 1and 2 show that the percentage drug released by the tablets generally increased with time, but the rate of this release is slowest with the kaolinite (KO) tablets which woefully failed the dissolution/drug release tests - it required $60 \mathrm{~min}$ to release a maximum of $0.39 \%$ of the active ingredient, compared to MS tablets which released $74.10 \%$ within $30 \mathrm{~min}$ (Fig. 1). This result is in tandem with the findings of Anthony et al., 2003, who observed that even though kaoline enhanced good quality tableting, it adversely affected the tablet dissolution and release of the active drug. This property of KO is not unconnected with the adsorptive property of kaolinite, particularly the silica moiety in the structure (Windholz, 1976; Depasse, 1978).
On the other hand, the $15 \%$ NaMMT tablets easily passed the dissolution/drug release tests, having released $75.40 \%$ of the active ingredient within $30 \mathrm{~min}$. This fares even better then the MS tablets (reference standard) which released $74.10 \%$ within 30min. A graph of percentage drug released vs time (min) (Fig. 2) clearly shows that the rates of drug release (slopes) due to the $15 \%$ NaMMT and MS tablet are in tandem. The impressive dissolution/drug-release characteristics of NaMMT tablets are correlated with the high powder porosity and disintegration quality of NaMMT. This may be attributed to reasonably high electronegativity, high hydration energy and the small size of $\mathrm{Na}$ ions (compared with that of $\mathrm{Al}$ and $\mathrm{Si}$ ions in kaolinite), coupled with capillary actions; these most likely encouraged large water uptake leading to fast disintegration and dissolution of the tablets with the attendant bioavailability of the active ingredients (Washburn, 1921; Selkirk and Ganderton, 1970; Lee, 1996; Shannon, 1976).

Table 1: Some physical characteristics of NaMMT, KO and MS powders.

\begin{tabular}{|c|c|c|c|c|}
\hline $\begin{array}{l}\mathbf{S} / \\
\mathbf{N}\end{array}$ & $\begin{array}{l}\text { Physical } \\
\text { characteristics }\end{array}$ & $\begin{array}{l}\text { Sodium montmorillonite } \\
\text { (NaMMT) }\end{array}$ & Kaolin (KO) & $\begin{array}{l}\text { Reference standard: } \\
\text { Maize Starch B.P. (MS) }\end{array}$ \\
\hline 1 & $\begin{array}{ll}\begin{array}{l}\text { Swelling } \\
\text { (degree) }\end{array} & \text { capacity }\end{array}$ & $\begin{array}{l}1.81 \\
(0.025)^{*}\end{array}$ & $\begin{array}{l}1.40 \\
(0.30)\end{array}$ & $\begin{array}{l}1.56 \\
(0.31)\end{array}$ \\
\hline 2 & $\begin{array}{l}\text { Water retention } \\
\text { capacity }(\%)\end{array}$ & $\begin{array}{l}2.90 \\
(0.45)\end{array}$ & $\begin{array}{l}1.80 \\
(0.38)\end{array}$ & $\begin{array}{l}3.04 \\
(0.35)\end{array}$ \\
\hline 3 & Bulk density & $\begin{array}{l}0.40 \\
(0.03)\end{array}$ & $\begin{array}{l}0.50 \\
(0.04)\end{array}$ & $\begin{array}{l}0.56 \\
(0.03)\end{array}$ \\
\hline 4 & Tapped density & $\begin{array}{l}0.63 \\
(0.02)\end{array}$ & $\begin{array}{l}0.83 \\
(0.01)\end{array}$ & $\begin{array}{l}0.71 \\
(0.04)\end{array}$ \\
\hline 5 & $\begin{array}{l}\text { True } \\
\left(\mathrm{g} / \mathrm{cm}^{3}\right)\end{array}$ & 2.00 & 2.50 & 1.72 \\
\hline 6 & Hausner's ratio & 1.56 & 1.43 & 1.27 \\
\hline 7 & $\begin{array}{l}\text { Angle of repose } \\
\text { (degree) }\end{array}$ & 40.20 & 34.40 & 56.00 \\
\hline 8 & $\mathrm{pH}$ & 8.49 & 4.95 & 6.90 \\
\hline 9 & $\begin{array}{l}\text { Powder } \\
(\%)\end{array}$ & 30.00 & 20.00 & 31.94 \\
\hline
\end{tabular}

*Standard deviation in parenthesis.

Table 2: Some physical characteristics of paracetamol tablets compounded with NaMMT, KO or MS as disintegrant at different concentrations.

\begin{tabular}{|c|c|c|c|c|c|c|c|c|}
\hline \multirow[t]{2}{*}{$\mathbf{S} / \mathbf{N}$} & \multirow[t]{2}{*}{ Tablet properties } & \multicolumn{3}{|c|}{$\begin{array}{l}\text { Sodium } \\
\text { montmorillonite } \\
\text { (NaMMT) }\end{array}$} & \multicolumn{3}{|c|}{$\begin{array}{l}\text { Kaolinite } \\
\text { (KO) }\end{array}$} & \multirow[t]{2}{*}{$\begin{array}{l}\text { Reference } \\
\text { standard: Maize } \\
\text { starch B.P (MS) } \\
10 \%\end{array}$} \\
\hline & & $5 \%$ & $10 \%$ & $15 \%$ & & & & \\
\hline 1 & Hardness $(\mathrm{kg} / \mathrm{N})$ & $\begin{array}{l}5.00 \\
(0.02)^{*}\end{array}$ & $\begin{array}{l}7.00 \\
(0.01)\end{array}$ & $\begin{array}{l}8.50 \\
(0.01)\end{array}$ & $\begin{array}{l}4.00 \\
(0.02)\end{array}$ & $\begin{array}{c}7.00 \\
(0.01)\end{array}$ & $\begin{array}{r}6.50 \\
(0.02)\end{array}$ & $\begin{array}{l}8.01 \\
(0.01)\end{array}$ \\
\hline 2 & Friability (\%) & 0.20 & 0.19 & 0.19 & 0.23 & 0.20 & 0.25 & 0.46 \\
\hline 3 & Thickness (mm) & $\begin{array}{l}0.33 \\
(0.01)\end{array}$ & $\begin{array}{r}0.33 \\
(0.01)\end{array}$ & $\begin{array}{c}0.33 \\
(0.02)\end{array}$ & $\begin{array}{l}0.33 \\
(0.01)\end{array}$ & $\begin{array}{l}0.30 \\
(0.01)\end{array}$ & $\begin{array}{c}0.30 \\
(0.01)\end{array}$ & $\begin{array}{l}0.33 \\
(0.02)\end{array}$ \\
\hline 4 & Diameter (mm) & $\begin{array}{l}12.32 \\
(0.01)\end{array}$ & $\begin{array}{l}12.32 \\
(0.01)\end{array}$ & $\begin{array}{l}12.32 \\
(0.01)\end{array}$ & $\begin{array}{l}12.32 \\
(0.02)\end{array}$ & $\begin{array}{l}12.32 \\
(0.01)\end{array}$ & $\begin{array}{l}12.32 \\
(0.02)\end{array}$ & $\begin{array}{l}12.32 \\
(0.01)\end{array}$ \\
\hline 5 & Mean weight (g) & $\begin{array}{l}0.52 \\
(0.02)\end{array}$ & $\begin{array}{c}0.52 \\
(0.02)\end{array}$ & $\begin{array}{r}0.52 \\
(0.02)\end{array}$ & $\begin{array}{l}0.52 \\
(0.01)\end{array}$ & $\begin{array}{l}0.52 \\
(0.01)\end{array}$ & $\begin{array}{c}0.52 \\
(0.01)\end{array}$ & $\begin{array}{l}0.52 \\
(0.02)\end{array}$ \\
\hline 6 & Disintegration time & 31.00 & 12.00 & 2.10 & 45.00 & 46.00 & 48.00 & 1.54 \\
\hline
\end{tabular}

\footnotetext{
*Standard deviation in parenthesis
} 


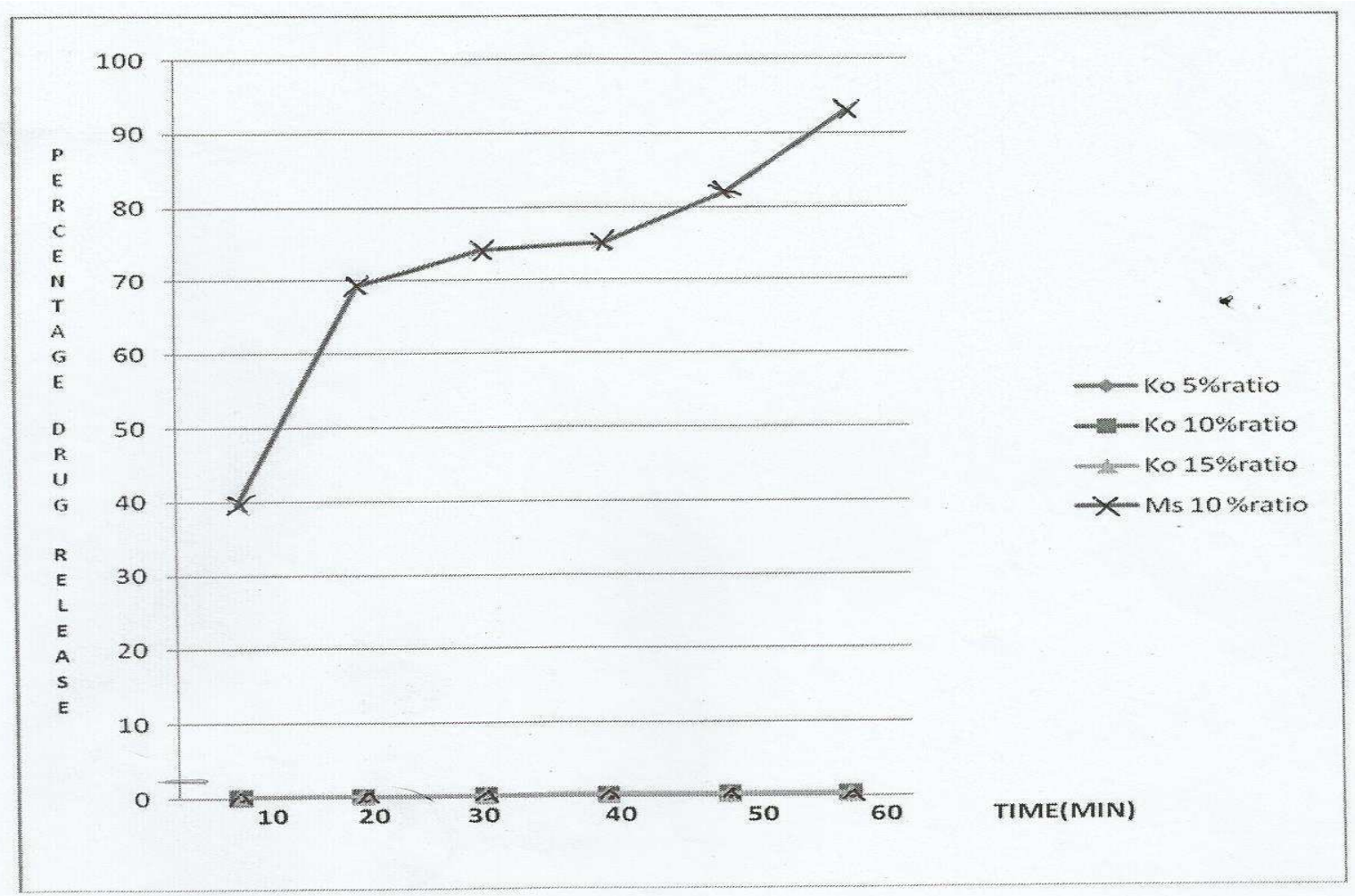

Fig. 1: Percentage drug-release during the dissolution test of KO relative to MS.

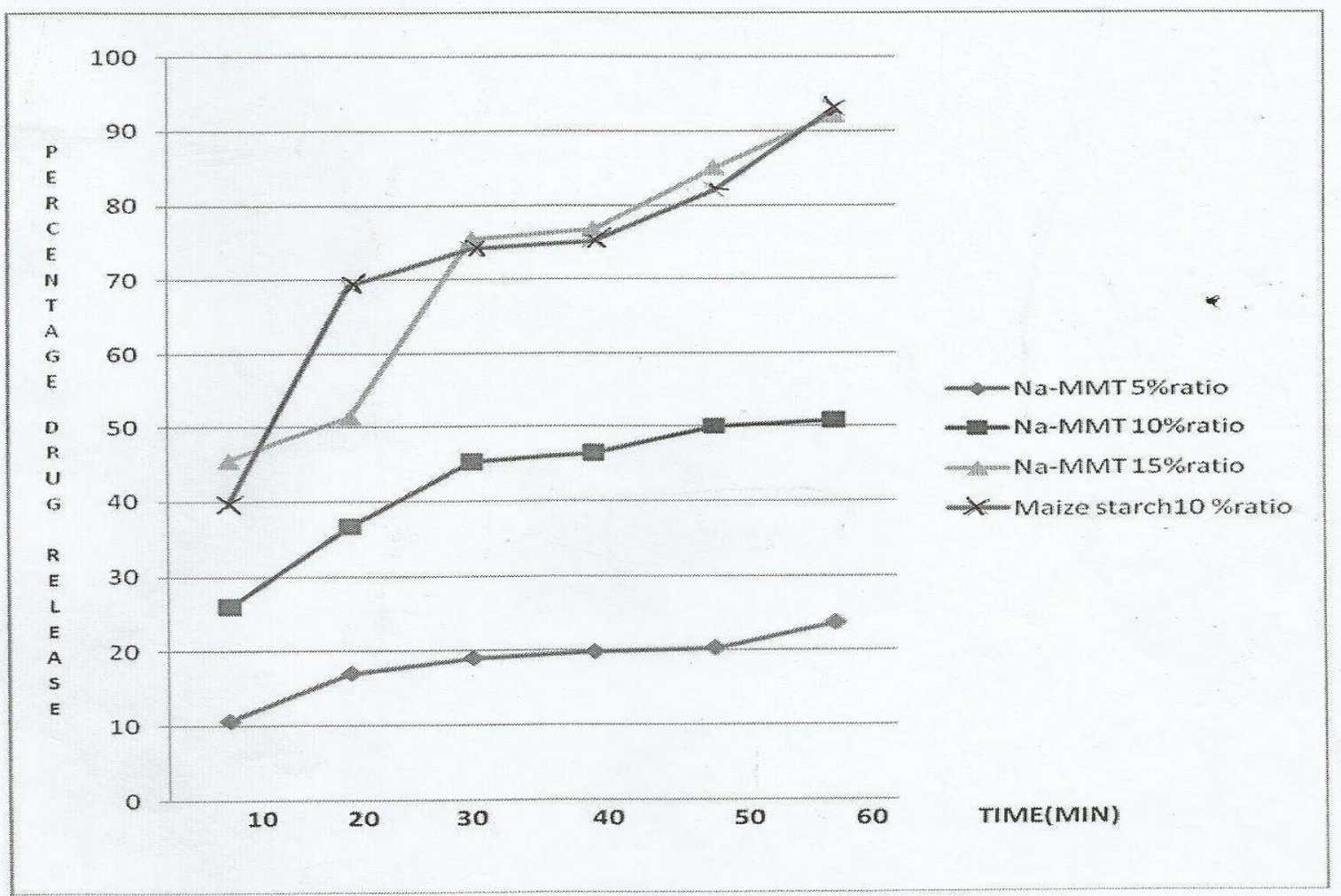

Fig. 2: Percentage drug-release during the dissolution test of NaMMT relative to MS.

\section{CONCLUSION}

In the light of the powder properties of the disintegrants, tablets qualities and dissolution/drugrelease characteristics of the various tablets, it is clear that the sodium montmorillonite (NaMMT) may hold great prospect as a disintegrant in formulating and compounding some compact, solid dosages. In this work the paracetamol tablets compounded with $15 \%$ NaMMT emerges as the optimum formular. 


\section{REFERENCES}

Alanzi, F.K. (2007). Evaluation of spray and freez dried excipient bases containing disintegration accelerators for the formulation of metoclopramide orally disintegrating tablets. Saudi Pharm. J. 15:105-119.

Amodu, Y. (2011). Evaluation of millet starches as tablet binders and disintegrants. M.Sc. Thesis in Pharmaceutics. Department of Pharmaceutics and Pharmaceutical Microbiology, Faculty of Pharmaceutical Sciences, Ahmadu Bello University, Zaria Nigeria.

Anthony, O.O., Cyril, O.U., Lucky, O.O. and Jessica, D.Z. (2003). Adsorptive property of kaolin in some drug formulations. Tropical $\mathrm{J}$. Pharm. Res.2 (1): 155-159

Bai, G., Wang, Y, and Armenante, P.M. (2011). Velocity profile and shear strain rate variability in the USP dissolution testing apparatus at different impeller agitation speeds. Int. J. Pharm.403 (1-2):1-14.

Bergaya, F., Theng, B.K., Lagarly, G. (2006). Hand book of clay science, $1^{\text {st }}$ edn. Elsevier Publications, Amsterdam. Pp. 717-741.

Bowen, F.E. and vadino, W.A.(1984). A simple method for differentiating sources. Drug. Dev. Ind. Pharm.10:505-511.

British Pharmacopoeia (2002). Vol. 1I. Stationary Office Ltd. St. Clement House, 2-16 Colegate, Norwich. P. A236.

Depasse, J. (1978). Interaction between silica and hydrophobic cations. Br. J. Ind. Med.35(1): 32-34.

Hill, P.M. (2006). Effect of compression force and cornstarch on tablet disintegration time. $J$. Pharm. Sci.65(11):1694 - 1697.

Iwuagwu, M.A. and Okoli, P.C (1992). Disintegrant properties of pregelatinized cassava and white yam starches. Pharm. World J. 9 (2):49-53.

Jideonwo, A., Okolo, P.O. and Osuoji, O.U. (2013). Powder properties of blends of starch and polyvinyl alcohol and their biodegradation characteristics. Biol. and Environ. Sci. J. for the Tropics (BEST). 10 (2): 268-271.

Kloprogge, J.T., Komarneni, S. and Amonette, J.E. (1999). Clays. Clay Miners. 47: 529.

Komblum, S.S. and Stoopak, S.B. (1973). A new tablet disintegrant agent: scrosslinked polyvinylpyrrolidone. J. Pharm. Sci. 62 (1): 43-49.

Lagaly, G. (2006). Colloidal clay science in: Handbook of clay science. Elsevier, Amsterdam. Pp. 141-245.

Lagaly, G. (1989). Ingredients of flow of kaolin and bentonite dispersion. Applied Clay Science4:105-123.

Lee, J.D. (1996). Concise inorganic chemistry. $5^{\text {th }}$ edn. Blackwell Science, Ltd. Oxford. Pp $160,164,441$.

Nwuluka, N.C., Idiakhoa, B.A., Nep, E.I., Ogaji, L. and Okafor, I.S. (2010). Formulation and evaluation of paracetamol tablets manufactured using the dried fruit of Phonix dactyl lifera linn as an excipient. Research in Pharm. Biotech. 2 (3): 25-32.

Odeniyi, M.A., Onu, R.N. and Adetunji, O.A. (2011). Evaluation of bioadhesive of natural and modified banana starches. East and central African J. of Pharm. Sci.14,34-42.

Oladimeji, O.O., Ifudu, N.D. and Ojo, A. (1997). Evaluation of kaolin powder as a lubricant in tableting. J. Pharm. Sci. Pharm. Prac. 3 (1): 13-16.

Olayemi, O.J. (2008). Comparative binding effects of wheat, rice, and maize starches in chloroquine phosphate tablet formulation. Res J. App. Sci. Eng. \& Tech.1 (2): 77-80.

Onyekweli, A. O. (1985). Binding disinterant properties of a local starch obtained from Musa Sapientum. Nig. J. App. Sci. 3(1): 33-43.

Raymond, C.R., Paul, J.S. and Scian, C.O. (2006). Handbook of pharmaceutical excipient, $5^{\text {th }}$ edn. Pharmaceutical Press, London. P.82.

Reghvendra, D. and Saraswathi, R. (2012). Nanoclay and drug delivery system. Int. J. Phar. World Research. 3 (3): 19-23.

Ring, S.G (1985). Some studies on gelatine. Starch.37:80-87.

Saleemula, K., Ramu, G., Krisha, G.M., Jayaveera, K.N. and Chetan, B. (2010). Tablet disintegrant activities of new starch from immature pepino fruit. J. Sci. Ind. Res. 70: $149-155$

Selkirk, A.B. and Ganderton, D. (1970). Influence of wet and dry granulation methods on the pore structure of lactose tablets. $J$. Pharm. Pharmacol, 22 (S):86-94

Shannon, R.D. (1976). Revised effective ionic radii. Acta Cryst., A 32: 751-767

Van, O.H. (1977). An introduction to colloidal chemistry, $2^{\text {nd }}$ edn. John Wiley. New York. Pp. 318.

Washburn, E.W. (1921). The dynamics of capillary flow. Phys. Rev. 17: 273-283.

Windholz, M. (1976). The mark index - an encyclopaedia of chemicals and drugs, $9^{\text {th }}$ edn. Merk \& Co. Ind., Ralway, USA. P. 693.

Yuan, J. and Murray, H.H. (1997). The importance of crystal morphology on the viscosity of concentrated suspensious of kaolin. Applied Clay Science. 12: 209-219. 